\title{
PENGEMBANGAN KOLEKSI DIGITAL DALAM MEMBANGUN PERPUSTAKAAN DIGITAL DI PERPUSTAKAAN UNIVERSITAS ISLAM NEGERI ALAUDDIN MAKASSAR
}

\author{
Andi Muhammad Aminullah \\ Universitas Islam Negeri Alauddin Makassar, Sulawesi Selatan, Indonesia \\ andy.oxide@gmail.com \\ Iskandar \\ Universitas Hasanuddin Makassar \\ M. Dahlan M. \\ Universitas Islam Negeri Alauddin Makassar
}

\begin{abstract}
Abstrac
This thesis discusses the development of digital collections in building digital library at the Alauddin Islamic State University of Makassar. The purpose of this research is to know: 1). Form of development of digital library collection at Alauddin Islamic State University of Makassar library, 2). The constraints development of a digital library collection at the Alauddin State Islamic University of Makassar library. The study was qualitative descriptive research using managerial and pedagogical approaches. Sources of data were the primary data source consisting of head of the library and repository staff, and secondary data obtained from the references, either in the forms of magazines, journals, articles or a variety of relevant research results. Interview guide and documentation were employed as research instruments and observation, interviews, as well as documentation were utilized as data collecting methods. The data gathered were analyzed and processed through several stages, namely data collection, data
\end{abstract}


reduction, data presentation, and drawing conclusion. The study results revealed that first, development of digital collections in building digital libraries at the Alauddin state Islamic University of Makassar library itself has been carried out, development of facilities and infrastructure, human resources competent in digitising activities. Second, budget procurement constraints, device requirements and addition of human resources in the development of digital collections. The implications of this study were expected supporting facilities and infrastructure in the development of digital collections in the library of Alauddin State Islamic University Makassar are more concerned, and is expected to be the attention of the rectorate of Alauddin State Islamic University of Makassar in facing the shortage of experts, especially in the digitization section of collection.

Keywords: digitalization, collection, digital library

\begin{abstract}
Abstrak
Tesis ini membahas tentang Pengembangan Koleksi Digital dalam Membangun Perpustakaan Digital di Perpustakaan Universitas Islam Negeri Alauddin Makassar. Tujuan dari penelitian ini yaitu untuk mengetahui: 1). Bentuk pengembangan koleksi perpustakaan berbasis digital di perpustakaan UIN Alauddin Makassar, 2). Untuk mengetahui kendala dalam pengembangan koleksi perpustakaan berbasis digital di Perpustakaan UIN Alauddin Makassar. Jenis penelitian ini adalah penelitian deskriptif kualitatif dengan menggunakan pendekatan managerial, dan pedagodik. Sumber data dalam penelitian ini yaitu sumber data primer yang terdiri dari kepala perpustakaan dan staf repository, dan sumber data sekunder yang diperoleh dari referensi, baik berupa majalah, jurnal, artikel dan berbagai hasil penelitian yang relevan. Instrumen penelitian ini menggunakan panduan pedoman wawancara, dan dokumentasi. Metode pengumpulan data menggunakan observasi, wawancara, dan dokumentasi. Adapun teknik pengolahan dan analisis data melalui beberapa tahap yaitu, pengumpulan data, reduksi data, penyajian data,
\end{abstract}


dan penarikan kesimpulan. Hasil penelitian ini menunjukkan bahwa pertama, pengembangan koleksi digital dalam membangun di perpustakaan Universitas Islam Negeri Alauddin Makassar sendiri telah terlaksana, pengembangan sarana dan prasarana, sumber daya manusia yang berkompeten dalam kegiatan digitasi. Kedua kendala pengadaan anggara, kebutuhan perangkat dalam dan penambahan sumber daya manusia dalam pengembangan koleksi digitial. Implikasi dari penelitian diharapkan sarana dan prasarana penunjang dalam pengembangan koleksi digital di perpustakaan UIN Alauddin Makassar sendiri lebih di perhatikan serta diharapkan perhatian rektorat UIN Alauddin Makassar dalam menghadapi kekurangan tenaga ahli alih media terkhususnya pada bagian digitalisasi koleksi.

Kata kunci : digitalisasi, koleksi, perpustakaan digital

\section{A. Pendahuluan}

Progresivitas sains dan teknologi komputer banyak mengubah tatanan hidup sebuah aturan atau sistem tertentu. Merujuk pada perkembangan teknologi tentunya sangat tepat jika layanan sebuah informasi sebuah perpustakaan dibuat modern dan lebih memudahkan pemustaka agar dapat menemukan informasi yang diinginkan. Perpustakaan merupakan tempat terkumpulnya bahan pustaka baik tercetak maupun terekam yang dikelola secara teratur dan sistematis. Perpustakaan merupakan salah satu sarana pelestarian bahan pustaka sebagai hasil budaya dan mempunyai fungsi sebagai sumber informasi ilmu pengetahuan, teknologi dan kebudayaan dalam rangka mencerdaskan bangsa dan menunjang pelaksanan pembangunan nasional. Hal ini tertuangkan dalam Undang-Undang Republik Indonesia Nomor 20 tahun 2003 tentang Sistem Pendidikan Nasional Pasal 45 (ayat 1) ${ }^{1}$ yang menyebutkan bahwa setiap satuan pendidikan formal dan non formal menyediakan sarana dan prasarana yang memenuhi keperluan

${ }^{1}$ Undang-Undang Republik Indonesia Nomor 20 tahun 2003 tentang Sistem Pendidikan Nasional 
pendidikan sesuai dengan pertumbuhan dan perkembangan potensi fisik, kecerdasan intelektual, sosial, emosional, dan kejiwaan peserta didik. Sarana yang dimaksud meliputi perpustakaan, laboratorium, dan sarana lain untuk menunjang kelancaran proses belajar mengajar. Berdasarkan hal tersebut, sehingga memberikan layanan secara merata kepada masyarakat untuk memanfaatkan perpustakan sebagai sumber informasi dan pengetahuan yang berhasil dan berdaya guna.

Perkembangan perpustakaan tidak pernah lepas dari perkembangan ilmu pengetahuan dan teknologi informasi. Hal ini dikarenakan perpustakaan sangat berkaitan erat dengan ilmu pengetahuan dan teknologi informasi. Ketiganya saling mendukung satu dengan lainnya. Perpustakaan memberikan kontribusi terhadap ilmu pengetahuan melalui penyimpan berbagai informasi dan sejarah perkembangan ilmu pengetahuan, sedangkan teknologi informasi memberikan dukungan pada kemudahan akses dan sistem informasi dalam sebuah perpustakaan. Seiring dengan perkembangan ketiganya, sekarang ini dikenal adanya perpustakaan digital atau (digital library) yang mampu menciptakan wadah yang lebih luas bagi hubungan ketiga hal tersebut di atas.

Perpustakaan adalah suatu unit kerja dari suatu bahan atau lembaga tertentu yang mengelola bahan pustaka, baik berupa bukubuku maupun bukan berupa buku yang diatur secara sistematis menurut aturan tertentu sehingga dapat digunakan sebagai sumber informasi oleh setiap pemakainya. ${ }^{2}$ Perpustakaan menurut UU No.43 Tahun 2007, Pasal 1 ayat 1, adalah institusi pengelola koleksi karya tulis, karya cetak, dan/atau karya rekam secara profesional dengan sistem yang baku guna memenuhi kebutuhan pendidikan, penelitian, pelestarian, informasi, dan rekreasi bagi pemustaka. ${ }^{3}$

${ }^{2}$ Supriyanto, W. \& Muhsin, A., Teknologi Informasi Perpustakaan: Strategi Perancangan Perpustakaan Digital. (Yogyakarta: Kanisius, 2008), h. 144

3 Undang-Undang Republik Indonesia No.43 Tahun 2007 Tentang Perpustakaan Pasal 1. h.2 
Identifikasi pemustaka dari segi kriteria dan menerapkannya pada evaluasi perpustakaan digital yang ada. Empat puluh delapan subjek diinstruksikan untuk mengembangkan dan membenarkan serangkaian kriteria penting untuk evaluasi perpustakaan digital. Pada saat yang sama, mereka diminta untuk mengevaluasi perpustakaan digital yang ada dengan menerapkan kriteria yang mereka miliki sedang berkembang. Kompilasi kriteria yang dikembangkan oleh peserta menunjukkan bahwa kegunaan dan pengumpulan kualitas adalah kriteria paling penting untuk mengevaluasi perpustakaan digital. Kualitas layanan, sistem efisiensi kinerja, dan permintaan pendapat pengguna juga dianggap kriteria penting. ${ }^{4}$

Sebagai salah satu unsur penunjang penyelenggaraan kegiatan pendidikan, perpustakaan merupakan pusat informasi, sumber ilmu pengetahuan dan teknologi, rekreasi serta pelestarian khasanah budaya bangsa. Sebagian besar perpustakaan kondisinya sangat menyedihkan. Perkembangan perpustakaan belum optimal karena faktor dana, budaya membaca di kalangan masyarakat serta tenaga perpustakaan yang kurang kompeten. Perpustakaan diharapkan sebagai pusat kegiatan pengembangan minat baca masyarakat supaya gemar membaca. Lebih lanjut Sinaga, menambahkan bahwa perpustakaan berfungsi sebagai pusat edukasi berarti perpustakaan harus berfungsi sebagai guru atau sebagai pusat sumber belajar yang menyajikan berbagai kebutuhan para pemustaka perpustakaan lainnya. ${ }^{5}$ Perpustakaan sebagai pusat rekreasi mengandung pengertian bahwa perpustakaan berfungsi sebagai sarana menyediakan bahan-bahan pustaka yang mengandung unsur hiburan yang sehat dan bermanfaat.

Pengembangan koleksi perpustakaan digital sampai saat ini masih menjadi wacana baru dalam dunia perpustakaan. Meskipun

${ }^{4}$ Hong iris xie. Evaluation of digital libraries: Criteria and problems from users perspectives .(Elsevies : libarary and information science research, 2006). h. 433 2005), h.26

${ }^{5}$ Dian Sinaga. Perpustakaan Sekolah. (Jakarta. Kreasi Media Utama. 
demikian, merupakan wacana yang tergolong baru, pertumbuhan perpustakaan digital telah melaju dengan pesat. Saat ini, hampir semua perpustakaan tengah berlomba untuk membangun perpustakaan digital.

Pembangunan perpustakaan digital tidak hanya berhenti pada penyediaan koleksi digital beserta infrastruktur pendukungnya. Pada dasarnya perpustakaan digital bukan perpustakaan jenis baru karena masih melaksanakan prinsip-prinsip dasar perpustakaan, hanya saja didukung dengan sentuhan atau kombinasi teknologi informasi dapat mewujudkan perpustakaan yang lebih modern, lengkap, mudah dijangkau dan user friendly dengan pengelolaan koleksi nasional maupun daerah.

Digitalisasi telah mengubah cara pandang pemustaka tentang melestarikan ilmu pengetahuan. Mayoritas perpustakaan saat ini adalah perpustakaan hybrid. Perpustakaan yang memiliki sarana dan prasarana yang memadai dimana berlangganan sumber daya yang berbeda dalam format yang berbeda. Beberapa format umum adalah e-journals, serial, print monographs, CD dan DVD. Komponen utama kerangka perpustakaan hybrid adalah repositori, sistem pegangan, dan sistem pencarian infromasi.

Setiap kemajuan dalam teknologi informasi hanya akan berguna jika kita tahu cara menggunakannya. Istilah kesenjangan digital digunakan untuk menggambarkan kesenjangan antara mereka yang memiliki pengetahuan teknologi informasi dan mereka yang tidak.

Berdasarkan latar belakang, maka yang menjadi fokus dalam penelitian ini adalah bentuk pengembangan koleksi berbasis digital di perpustakaan UIN Alauddin Makassar dan kendala dalam pengembangan koleksi digital dalam membangun perpustakaan digital di perpustakaan UIN Alauddin Makassar.

Tujuan penelitian dari penulisan penelitian ini adalah untuk mengetahui pengembangan koleksi perpustakaan berbasis digital di perpustakaan UIN Alauddin Makassar dan kendala dalam 
pengembangan koleksi digital dalam membangun perpustakaan digital di perpustakaan UIN Alauddin Makassar.

Jenis penelitian ini adalah penelitian deskriptif kualitatif $f^{6}$. Penelitian kualitatif bertujuan memahami fenomena yang terjadi dalam suatu komunitas dalam bentuk deskriptif dengan pendekatan studi kasus (case study) yaitu studi yang bersifat komprehensif, intens, rinci dan mendalam serta diarahkan sebagai upaya penelaahan masalah-masalah dalam hal ini adalah bentuk pengembangan koleksi digital dalam membangun perpustakaan berbasis digital di pepustakaan UIN Alauddin Makassar dan kendala dalam pengembangan koleksi digital dalam membangun perpustakaan digital di perpustakaan UIN Alauddin Makassar. Menggunakan pendekatan manajerial dan pendekatan pendagogik serta metode pengumpulan data yang digunakan adalah observasi, wawancara dan dokumentasi.

\section{B. Pembahasan}

\section{Pengembangan koleksi digital di perpustakaan UIN Alauddin Makassar}

Pengembangan koleksi perpustakaan tidak terlepas dari perkembangan teknologi yang semakin harinya semakin berkembang dengan pesatnya, perpustakaan di tuntut agar selalu bertransformasi seringing pesatnya kemajuan teknologi.

Sebagai sebuah organisasi perpustakaan harus mampu menjadi wadah edukasi bagi masyarakat yang sebagaimana menjalani fungsingnya sebagai pencerdas bangsa, seperti yang tetuang dalam tri dharma perguruan tinggi, perpustakaan mempunyai andil besar dalam kemajuan sumber daya manusia, perpustakaan bukan hanya tempat yang selalu berisikan bukubuku dalam bentuk fisik semata.

Perpustakaan era modern ini mulai melakukan kegiatan digitalisasi koleksi yang dimana tuntutan masyrakat akan

${ }^{6}$ Sayuthi Ali, Metodologi Penelitian Agama: Pendekatan Teori dan Praktek, Ed.I (Cet. I;Jakarta: PT Raja Grafindo Persada, 2002), h.59. 
informasi cepat, mudah, tepat dan mudah di akses, pengembangan koleksi perpustakaan sendiri mengalami transformasi yang sangat signifikan dari awalnya koleksi bahan pustaka di perpustakaan bersifak buku-buku menjadi koleksi yang bersifat digital.

Bentuk pengembangan koleksi digital di Perpustakaan UIN Alauddin Makassar.

Setiap koleksi yang di ada di perpustakaan merupakan sebuah informasi yang sangat berharga, dimana koleksi di jaga keutuhan isi informasinya, pengembangan teknologi membuat perpustakaan mengemas sebuah informasi menjadi terobosan baru dalam melayani kebutuhan pemustaka, koleksi digital menjawab berbagai macam keresahan pemustaka yang ingin mengakses informasi dimana saja dan kapan saja.

Bentuk pengembangan koleksi digital di perpustakaan UIN Alauddin Makassar sendiri, pada awalnya buku masih bersifat tercetak, setelah itu buku kemudian di scan dengan menggunakan alan scan khusus, setalah discan file belum bisa langsung disave di karenakan harus masuk dalam tahap editing yang dimana tahap editing ini file di croop agar sesuai satu sama lain halamanya agar ada nilai estetika sendiri dari kerapianya tersebut, kemudian file di kompres ukuranya. Baik buku ataupun jurnal-jurnal karya para dosen UIN Alauddin Makassar di input dalam repository UIN Alauddin, laporan penelitian tahun 1990an, prosiding, karya tulis ilmiah baik itu skripsi, tesis dan disertasi, dan karyakarya yang berkaitan mengenai sejarah.

\section{Pengembangan sarana dan prasana penunjang dalam} pengembangan koleksi digital di Perpustakaan UIN

\section{Alauddin Makassar}

Pengembangan koleksi digital di perpustakaan harus di dukung oleh sarana dan prasarana yang memadai di karenakan pengembangan koleksi dapat di lakukan secara 
maksimal apabila sarana dan prasana di perpustakaan di perbaharui agar lebih mutakhir dalam melakukan kegiatan digitalisasi koleksi di perpustakaan.

Sarana dan prasarana baik itu elektronik untuk menyimpan, mengelola, dan menyapaikan informasi kepada pemustaka harus di lakukan pengembangan agar mencapai kepuasan pemustaka itu sendiri.

Pihak perpustakaan dalam hal ini terkhususnya staf repository di berikan arahan oleh pihak pustipad di bawah naungan rektorat UIN Alauddin Makassar agar mebuat database berkaitan dengan koleksi digital, kemudian diarakan untuk memasang aplikasi SLIMS agar menunjang semua aspek berkaitan dengan kegiatan digitalisasi koleksi di perpustakaan UIN Alauddin, Pengembangan sarana dan prasarana menjadi hal yang penting dalam pengembangan koleksi digital di perpustakaan apabila sarana dan prasaran tidak kembangkan maka jalannya proses digitalisasi koleksi di perpustakaan menjadi tertunda bahkan terbengkalai, hal ini menjadi sorotan penting terkhusunya pihak rektorat yang menaungi perpustakaan UIN Alauddin Makassar sehingga dapat memaksimalkan pengembangan sarana dan prasarana dalam menunjang kegiatan ditalisasi koleksi di perpustakaan.

\section{Pengembangan sumber daya manusia di perpustakaan UIN Alauddin Makassar}

Demikian dengan halnya pengembangan sumber daya manusia yang sudah selayaknya mengikuti perkembangan teknologi informasi yang berjalan Pengembangan koleksi digital tidak terlepas dari adanya manusia yang menjalankan sistem dalam digitalisasi koleksi di perpustakaan, staf atau pustakawan yang berperan dalam alih media koleksi yang pada awalnya bersifat fisik menjadi elektronik, pengembangan 
sumber daya manusia merupakan salah satu tolak ukur keberhasilan pengembangan koleksi digital di perpustakaan.

Pengembangan sumber daya manusia di perpustakaan adalah suatu upaya untuk mengembangkan kualitas atau kemampuan agar mampu mengolah dan mengelola sumber daya dengan berbagai macam teknologi, sehingga dapat digunakan untuk melakukan tugas-tugas yang ada dalam sebuah organisasi perpustakaan serta mensejahterakan kebutuhan informasi kepada masyarakat secara optimal.

Pengembangan koleksi digital di perpustakaan mempunyai fungsi-fungsi dan proses-proses yang harus dilakukan untuk mencapai tujuan, atau visi dan misi organisasi tersebut. Hal ini termasuk memilih sumberdaya yang perlu diadakan untuk pengembangan koleksi, membuka akses, serta untuk mendistribusikan sumberdaya tersebut. Fungsi dan proses tersebut dilakukan dengan bantuan sumberdaya manusia dalam ruang lingkup perpustakaan tentunya.

Pengembangan sumber daya manusia di perpustakaan UIN Alauddin Makassar sendiri dirasa masih sangat perlu di karenakan teknologi yang berkembang semakin harinya selalu mengalami perubahan, sebagaimana teknologi terus di perbaharui begit pula layaknya sumber daya manusia di perpustakaann. pengembangan sumber daya manusia menjadi prioritas utama perpustakaan agar dapat menunjukan taringnya dalam era tekhnologi informasi sekarang ini, di harapkan perpustakaan dapat memberikan pelatihan-pelatihan guna mempertahakan eksistensi manusia sebagai penggerak tekhnologi di belakang layar, alangkah baiknya anggaran untuk pelatihan di pindahkan untuk halhal yang lebih penting salah satunya penyediaan perangkat ditialisasi koleksi. 


\section{Kendala Dalam Pengembangan Koleksi Digital di Perpustakaan UIN Alaudiin Makassar}

Pengembangan perpustakaan digital di Indonesia dimulai di lingkungan perguruan tinggi, pengembangan koleksi digital di Indonesia sendiri masih menghadapi pasang surut dalam upaya membangun perpustakaan yang bersinergi dengan tekhnologi. Hingga saat ini pengembangan koleksi digital bagi perpustakaan di Indonesia masih menemui banyak kendala baik teknis, finansial, maupun kebijakan. Walaupun demikian, semangat untuk mengembangkan koleksi digital para pustakawan di Indonesia tidak pernah berkurang.

Selain memiliki banyak keuntungan dari koleksi digital tentu saja ada kendala dalam pengembangannya, segala aspek harus tinjau dalam mengembangkan koleksi digital di perpustakaan, maka dari itu perlunya keterkaitan semua pihak agar pengembangan koleksi di perpustakaan berjalan secara maksimal.

\section{Kendala penyediaan anggaran dalam pengembangan koleksi digital di Perpustakaan UIN Alauddin Makassar}

Perpustakaan harus bersikap mandiri dalam masalah penyediaan anggaran yang di berikan oleh instansi yang menaunginya, perpustakaan UIN Alauddin sendiri mendapatkan anggaran secara langsung dari rekotrat UIN Alauddin, sehingga setiap anggaran yang masuk dapat di pergunakan sebaik mungkin dan maksimal sesuai dengan kebutuhan yang di perlukan oleh perpustakaan, sehingga tidak ada pengeluaran yang disia-siakan.

Kendala dalam pengembangan koleksi digital di perpustakaan tentu saja bermacam-macam, anggaran merupakan hal yang penting di karenakan kita ketahui secara umum bahwasanya pengadaan perangkat baik itu hardware dan software, Dalam memilih perangkat ini diharapkan mampu untuk menyesuaikan diri dengan kebutuhan dan kemampuan anggaran yang miliki. tidak hanya sampai disini 
saja. Gaji para staff honorer perpustakaan harus di bayar dan itu memerlukan anggaran yang tidak sedikit.

Kendala penyediaan anggaran di perpustakaan UIN Alauddin Makassar sendiri langsung dari rektorat, pihak perpustakaan sendiri hanya memberikan rekomendasi apa saja yang harus di sediakan atau dibutuhkan oleh pihak perpustakaan. Untuk penyediaan anggaran dalam pengembangan koleksi digital di rasa masih sangat perlu diajukan kembali ke pihak rektorat, hal ini dikarenakan anggaran untuk pengembangan koleksi digital di perpustakaan UIN Alauddin Makassar sendiri masih sangat minim, kita ketahui bersama bahwa perpustakaan UIN Alauddin Makassar adalah perpustakaan terbesar se Indonesia timur.

\section{Kendala akan kebutuhan perangkat dalam menunjang pengembangan koleksi digital di perpustakaan UIN Alauddin Makassar}

Perkembangan informasi global semakin tampak dirasakan oleh masyarakat sebagai pemustaka, baik dalam kebutuhan barang, layanan maupun jasa. Kebutuhan akan layanan yang prima tentunya membutuhkan suatu perangkat yang berkelas. Dan salah satu alternatif yang saat ini lagi menjadi komoditi publik adalah berkembangnya penggunaan teknologi informasi yang bersinergi dengan operasional manajemen perpustakaan.

Kebutuhan akan perangkat baik itu perangkat keras dan lunak menjadi penunjang penting dalam kegiatan digitalisasi koleksi di perpustakaan, sehingga optimalisasi digitasi di perpustakaan dapat mencapai titik yang maksimal. Perangkat menjadi tolak ukur keberhasilan dalam pengembangan koleksi digital di perpustakaan. Disamping adanya sumber daya manusia yang memadai harus diringi dengan perangkat yang modern, perangkat keras dan lunak adalah hal yang tak 
terpisahkan dalam perpustakaan di era modernisasi seperti sekarang ini, sehingga koleksi digital di perpustakaan dapat dinikmati oleh pemustaka tanpa adanya kendala.

Kendala dalam pengembangan perangkat menjadi menjadi prolematika dan tantangan tersendiri bagi organisasi perpustakaan agar dapat berkembang dan memulai berbenah diri kearah yang lebih baik.

kendala dalam kebutuhan perangkat sebagai penunjang kegiatan digitalisasi koleksi di perpustakaan UIN Alauddin Makassar, kendala yang dihadapi salah satunya adalah perangkat untuk mendigitalisasikan koleksi cepat mengalami eror dan overheat, ketika pada saat melakukan scanning koleksi yang berjumlah ratusan halaman, sehingga butuh waktu kembali mendinginkannya, dan menyebabkan waktu yang di perlukan dalam melakukan kegiatan digitasi koleksi terhambat, baru-baru ini perpustakaan melakukan pengadaan tempat $\mathrm{CD}$ akan tetapi infrastruktur untuk sistem repository tidak ada, seharusnya ada perangkat alih media di ruangan pengolahan sehingga pembagian tugas menjadi efisien dan cepat dalam hal digitalisasi koleksi, ruangan multimedia juga tidak bisa digunakan sebagai tempat yang kompatibel untuk berbagai jenis koleksi digital.

\section{Kendala tenaga ahli alih media}

Alih media digital merupakan kegiatan melestarikan khasanah budaya bangsa dengan mengalih bentuk dari bentuk fisik sebuah koleksi ke bentuk/media digital. Alih media merupakan proses digitasi yaitu proses alih media dari media cetak seperti buku, majalah, koran, foto dan gambar ke dalam bentuk data digital yang dapat direkam, disimpan dan diakses melalui komputer atau media digital lainnya yang kompatibel.

Tenaga ahli alih media di perpustakaan harus mereka yang benar-benar paham akan penggunaan teknologi, 
terkhususnya teknologi yang berkaitan dengan alih media baik itu dari segi hardware maupun software, seorang staf alih media media adalah mereka yang ditunjuk oleh perpustakaan akan keahlianya, baik itu lulusan tekhnologi informasi ataupun mereka yang berasal dari ilmu perpustakaan bahkan apabila staff di berikan pelatihan tentang pengelolaan, tata cara digitasi koleksi bisa di pekerjakan oleh pihak perpustakaan, sehingga tidak ada alasan khusus bahwa perpustakaan tidak bisa melakukan kegiatan digitalisasi koleksi di perpustakaan.

Tenaga ahli alih media sendiri di perpustakaan UIN Alauddin Makassar terkhususnya pada bagian digitalisasi koleksi sampai saat ini belum ada dikarenakan pihak perpustakaan lebih mengfokuskan kepada proses digitasi koleksi terkhususnya buku-buku dari para dosen yang ingin mendigitalkan bukunya. Yang dimana staf repositroy mengambil alih bagian ini, adapun langkah baik kedepannya kepala perpustakaan berniat untuk membentuk tim dalam bidang digitalisasi koleksi sehingga pembagian kerja di perpustakaan UIN Alauddin Makassar sendiri agar dapat berjalan semaksimal mungkin, perlunya perhatian dari pihak rektorat dalam memberikan jalan tengah. Para staf repository Perpustakaan UIN Alauddin Makassar merasa perlunya di bentuk staf atau tim khusus untuk bagian digitalisasi koleksi di perpustakaan, dikarenakan staf repository sendiri sering berbenturan dengan proses digitasi koleksi apabila ada yang ingin mendigitalisasikan koleksi.

\section{Kesimpulan}

Pengembangan koleksi digital di perpustakaan Universitas Islam Negeri Alauddin Makassar sendiri telah terlaksana, bentuk pengembangan koleksi digital di perpustakaan UIN alauddin Makassar koleksi di alih media menjadi koleksi digital dalam bentuk pdf file, sarana, prasarana dan pengembangan sumber 
daya manusia sebagai penunjang kegiatan digitalisasi koleksi di perpustakaan UIN Alauddin Makassar sudah cukup memadai. Kendala dalam pengembangan koleksi dital di perpustakaan UIN Alauddin Makassar terletak pada kebutuhan akan perangkat dalam melakukan kegitatan digitalisasi koleksi di perpustakaan UIN Alauddin Makassar 


\section{DAFTAR PUSTAKA}

Ali, Sayuthi. Metodologi Penelitian Agama: Pendekatan Teori dan Praktek, Ed.I, Cet. I; Jakarta: PT Raja Grafindo Persada, 2002.

Iris, Hong xie. Evaluation of digital libraries: Criteria and problems from users perspectives. Elsevies : library and information science research, 2006.

Sinaga, Dian. Perpustakaan Sekolah. Jakarta : Kreasi Media Utama, 2005.

Supriyanto, W. \& Muhsin, A. Teknologi Informasi Perpustakaan: Strategi Perancangan Perpustakaan Digital. Yogyakarta: Kanisius, 2008. 